\title{
In and Out of the Mist: An Artistic Investigation of Borderland and Community
}

\begin{abstract}
By Yoong Wah Alex Wong *
The main concern of this research is to initiate a new artistic approach, with photography as a medium and an artistic form of investigation, into the borderland and community that exists from Western China to the Himalayan Region, in order to distinguish it from documentary photography. The borderland exists as an ambiguous territory between governance structures, and the movements of the borderland community often seek to surpass the command of the states. The ideas of inclusion and exclusion, identity within one's community, and the relationship on the borderlands are hard to clearly define. This research develops the hypothesis that borderless borderland is possible with the intervention of fog and mist.
\end{abstract}

Keywords: borderlands, borderless, identity, intervention, mist, photography.

\section{Introduction}

"It is through living that we discover ourselves, at the same time as we discover the world around us" Henri Cartier-Bresson (Goodreads, n.d).

From Western China to the Himalayan Region (Figure 1) there is a historically contingent society, developing both within the context of internal evolution and with the external effects of world history. The border takes on essential importance for China and the neighbouring countries since it serves as the fundamental attribute for literal, symbolic, historical and psychological justifications of identity. Due to the different historical and geographical experiences, the condition and relationship of borders vary regionally. Nevertheless, I do not endeavour to delve into the area of conflict resolution, political science or borderland interrogation analysis. My main intention is to use photography to explore, investigate and analyse the aesthetic of the borderlands that stretch from Western China to the Himalayan Region.

Every border area is different from each bordering country, and every border area is unique. The research focussed on investigating and exploring Western China to the Himalayan Region because Western China and the neighbouring Post-Soviet countries are rich in cultures. These interesting cultures differ in terms of art and traditional practice of daily life. Furthermore, as the roof of the world, the Himalayan region sets a challenge for me to explore its rare and unique landscape which separates the plains of the Tibetan Plateau from the Indian and Nepalese subcontinent. The Himalayas also shaped the cultures of South Asia where many of the Himalayan peaks are considered holy sanctuaries to Buddhism and Hinduism. Photography enabled me to both capture and spend time understanding the different ethnic groups of people, religions, festivals and traditional customs. Aim of this research is to document

*Faculty Member, Sabanci University, Istanbul, Turkey. 
the cultures, humans and nature, along these vast borderlands and to make a synthesis of the sense of fact and personal truth in producing creative artistic photographic works. The resultant photographic works are not the utmost important goal; rather, the process of discovery and reflection of the discovery are more crucial to this research. I intend to explore and capture the moment of borderlands encounters in an ambiguous and irresistible way for the viewer to ponder, which no other photographers have yet done in borderland photography. This research would envision compositions that would open up new boundaries and expression in photography. The process of discovering a new way to interpret the borderland is of the utmost importance in this research.

Figure 1. Photographing the Area from Western China to the Himalayan Region (In red line)

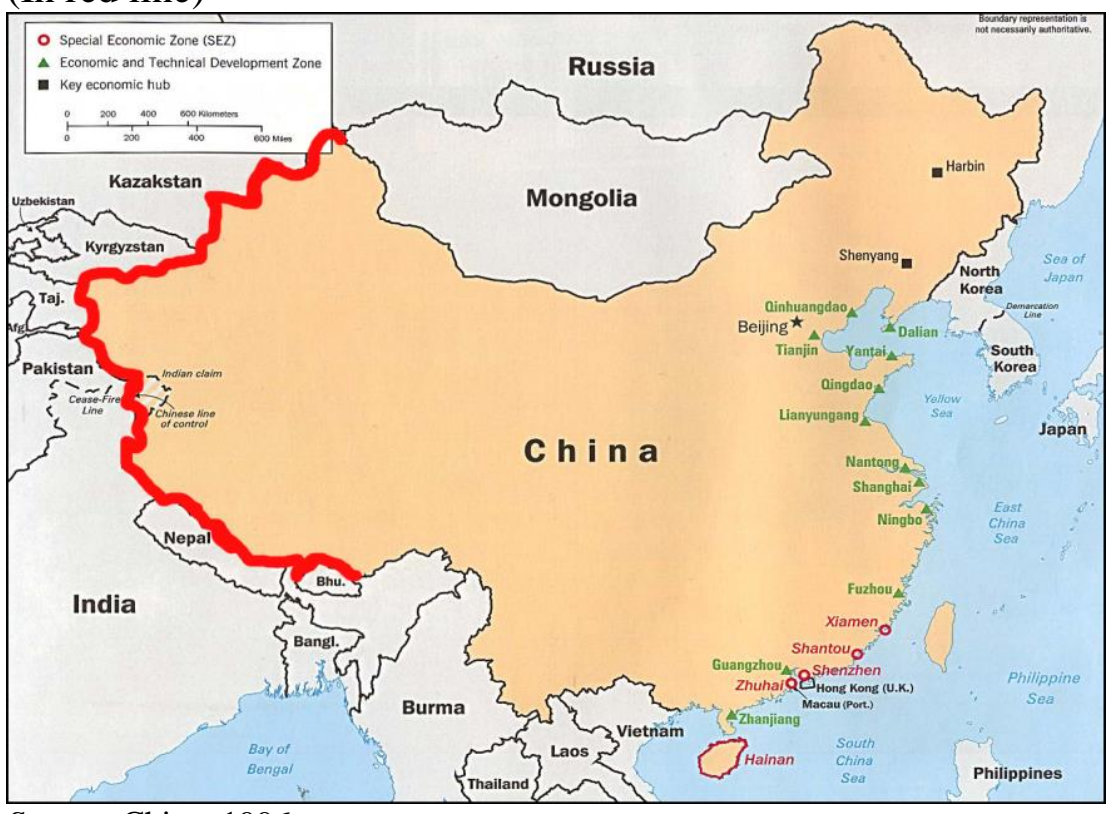

Source: China, 1996.

In stage 1 , the objective is to uncover the lifestyles, festivals and cultural activities like most of the documentary photographers who photographed the borderlands, in order to analyse their approaches better and review different possibility of image making.

In stage 2, to further explore and to visualise the borderlands in this region from an aerial point of view, to find out the amalgamated landscape and nature formation in this complicated borders region that connects different neighbouring countries.

In stage 3, to investigate the physical borders and connections (roads) that connects different neighbouring countries. This investigation could provide a better picture of the relationship between borderlanders (human), man-made structures and nature in this region.

In stage 4 , the final intended artistic study and findings are to achieve associated photography characteristic between documentary and contemporary conceptual photography. Utilising photography as the main medium in this 
investigation can shed some light on the past and current documentary photography agenda, to urge a new artistic intervention and create visual representation beyond documentation. This research will continue to uncover the magical and mysterious effects of fog and mist, bringing a whole new sense to documentary photography and contemporary photography.

The discovery of such magical transformation from a realistic visual to an art form through fog and mist intervention would creatively define photography as more than a medium of documentary where fog and mist could transform a real-life moment to an imaginative surrealistic space, at the same time challenging the notion of "border", where borderless borderland is possible.

\section{Methodology}

Photographers are usually attracted to and inspired by the freshness of a subject. Fredric Jameson described and suggested that there are more than enough similar images out there without needing a photographer to make new ones. When stylistic innovation is no longer possible in the world, what remains is an imitation of dead styles (Jameson, n.d.). Contemporary or postmodern art constantly requires the inevitable collapse of art and creativity. The Cruel Radiance by Susie Linfield noted the contemporary artist Richard Prince stated, "The only method to make it new, is to repeat and do it again" (Linfield, 2012).

The same book by Susie Linfield mentioned that Victor Burgin stated "Our conviction that we are free to choose what we make of a photograph hides the complicity to which we are recruited in the very act of looking" (Linfield, 2012). He commented that Sophie Calle's "voyeurism" and "prejudiced perception" could only lead to a miserable self-satisfaction.

High-modernist critics like the American photographer John Szarkowski received substantial criticism from the postmoderns, claiming that he had confined photography from political and social purposes. Nevertheless, documentary photography and photojournalism, grounded in the political and social, are equally opposed by modernist photographers and critics. They mock socially-conscious photojournalists who embrace outdated ideas on development and their views on reality as a necessity. Sometimes, documentary photography can be similar (war documentary) to watching a horror movie, putting on a scary mask to ignite fear, converting violence into fiction.

I see that while looking at a photograph, contemporary critics suggest that it is difficult for the viewer to find a moment of extraordinariness and originality as the photographer is unable to provide it. It is a false hallucination and a lost hope to entrust photography with a meaning. Meanwhile, some contemporary photography critics have refused the fundamental ideology of post-modernism. For example, Max Kozloff and Geoff Dyer, Rebecca Solnit and David Levi Strauss have replied to postmodern criticism without surrendering to it. In time, postmodern sarcasm may seem no longer in vogue.

The depiction of weak, defenseless people, as seen in many photographs, is a fake fantasy that many photographers deliberately create to gain recognition and 
fame. Carol Squiers depicted photojournalism as nothing more than representation of suffering and intense desperation. At the same time, Martha Rosler (Pachmanova, 2006, p. 109) went on to express her opinions on contemporary photojournalism as a fragmented, provoking, cunningly immoral, lip-smacking appreciation of unfamiliar vitality. Some documentary photographic works definitely match this definition. Peculiarly, Martha Rosler and her colleagues would reject provocative photography such as the works of American documentary photographer Eugene Richards and South African photographer David Goldblatt.

Figure 2. The Gray Drape by Martha Rosler

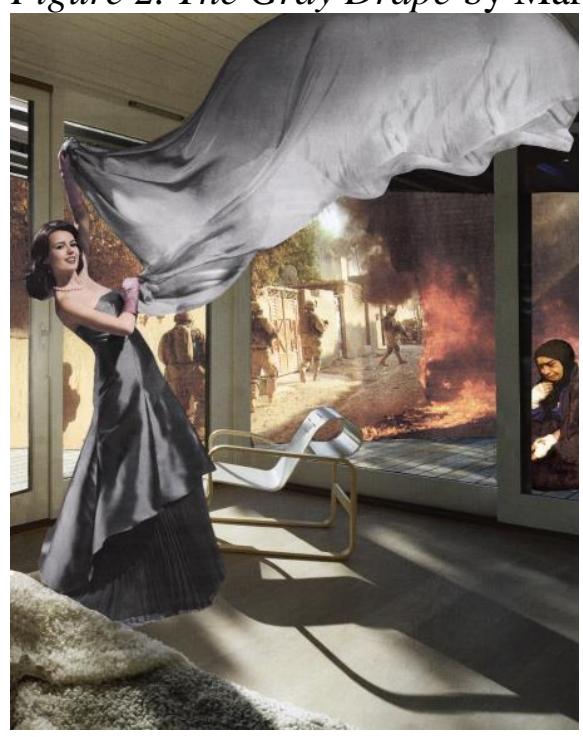

Source: Rosler, 2008.

Martha Rosler (Pachmanova, 2006, p. 109), however, mentioned in her writing, when she addressed the problem in the Vietnam War and Cold War during the 1950s, that war is the ultimate form of discrimination. Her artworks (Figure 2) often depicted the reality of urban glamour and modern life contrasted to the war scene in the background where she deliberately suggests that the USA's rhetoric of war is total paranoia, lasting even till today. I realize below provocative and imbalance visual continue to hits our current living conditions right on. One corner of the world is still experiencing an unpleasant threat of human aggression, yet other corner is enjoying to the fullest in an abundance of luxurious extravaganza, a reality in contrast. To me, it is somehow teasing the world and war documentary photography works, which mostly based on innocent and human conflict imagery.

The inconvenient truth is that documentary photography was first used to document historical wars, from landscape to city life. Fortunately, the use of documentary photography continues to enlighten viewers regarding many historical events, to diversify and extend storytelling as the archive of time. Unfortunately, the use of documentary photography in wars and storytelling of violence in the city is not advanced by many current photographers, who continue to chase and capture the sensational truths only. I strongly believe that 
documentary photography does not attract by provocative and unnerving images only, but gutsy photographers are very much addicted to capturing such defiant and electrifying images. In order to unveil the brutal fact, some photographers think violence and war images are highly anticipated because viewers are shocked by their unbearable moment of inhuman truth, whilst photographers continue to risk their lives for such horrific moments. How can such an immoral and cruel reality continue to happen, spreading like a virus in different corners of the world? Please make no mistake between "anticipation" and "appreciation". Both terms can be mixed up, resulting in mixed feelings when viewers look at these provocative war images. No doubt the good intention of photographers is to capture and transmit the truth, reminding us of what violence and war can cause and how. Yet, when we look at the current media, we find ourselves surrounded by such unpleasant news.

There are need for creative and innovative representation of documentary photography beyond the mode of direct point and shoot, slapping us with repulsive images. High-calibre photographers should push and advance their intellectual knowledge, rather than chasing potentially shocking images that would provide them with assured fame. A photographer should learn to exercise beyond his or her impulsive instinct and intuition. Finding subtle elements, unconventional representations and unusual metaphors to further elaborate what is already out in reality remains challenging, but necessary. Otherwise, without self-reflection and self-realisation, photographers can be ignorant or caught in the loop of a vicious circle, continuing to capture images that have been done for over a century. This realisation is an inspiration for change, and a motivation to work relentlessly towards betterment: betterment of visual representation, metaphorical meaning and the sense of morality behind the captured images (Verve, n.d.). It is especially poignant when whittled down to the core: a photographer who is willing to try to push beyond the boundary of conflictual images may find a universally identifiable sentiment to visualise, and may photograph the borderlands afresh. Clarity in photography is always good, but overclarity kills art. Therefore, I always prefer to photograph my subject in a way that would create an ambiguity and freedom of expression, arousing the viewers' attention and leading them to puzzle over it in terms of their own experiences and interpretations.

By understanding and being aware of the remarks from various photography critics and practical photographers from different backgrounds and ideologies, I begin to find my own way and stay truthful to my own photography perception. At the early stage, I tried direct documentary works by photographing the borderland in an obvious, sincere and truthful approach. Most of these early borderlands documentary works from Western China to the Himalayan Region are based on lifestyle, portraits, cultural activities and festivals (Figure 3).

The development of three photographic stages and associated visual strategies leading toward the discovery of the final In and Out of the Mist series - A resolution of the metaphorical significance of mist as a temporal suspension in this conflicted region. 
Figure 3. Procedure: Borderlands Photography

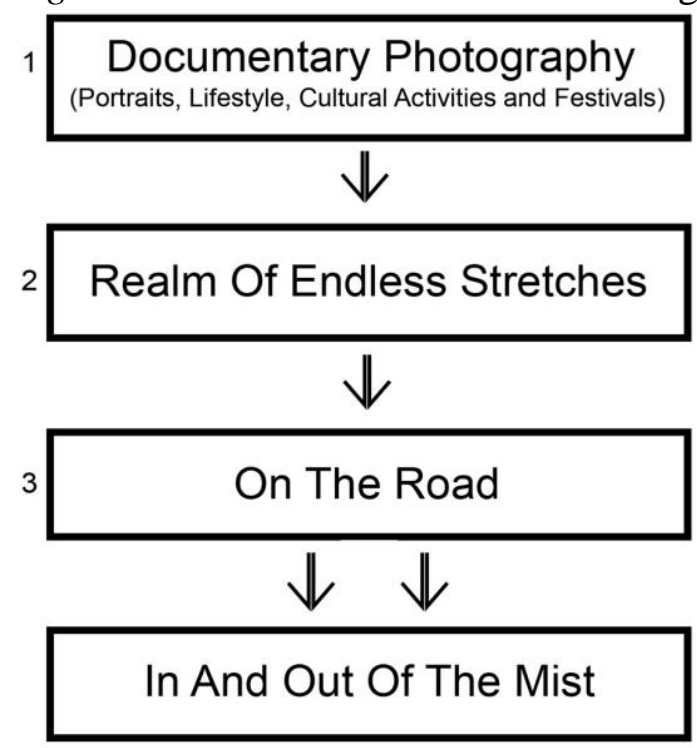

Source: Author's personal file.

\section{Procedure: Borderlands Photography}

\section{Stage 1: Documentary}

The best way to witness visual differences is to see, observe and analyse them. I would like to mention a few prominent documentary photographers, like Patrick Sutherland, Ami Vitale and Carolyn Drake, who work extensively in these borderland regions (Western China to the Himalayan Region).

Patrick Sutherland is a highly esteemed Professor working in the field of documentary photography and photojournalism, ethnographic recordings of the culture and the communities of Northern India and Western Tibet. His extensive research and photographing in Spiti for about two decades are noteworthy. I find Sutherland's and Tsering's essay regarding the little known sacred ritual of Tibetan Buddhism particularly noteworthy. I am saying this because I witnessed many events organised mainly for tourism purposes regarding Tibetan cultural and heritage tradition. These are easily accessible, colourful and spectacular events. As much as I have witnessed crazy saints at play in different local rituals and festivals in Tibet, the collection of different styles of costumes of the crazy saint by Sutherland amazed me. Tibetan Buchen performances combine the spiritual, the religious, social, sexual, and comedic overlapping human experience with Tibetan Buddhism's mythical story and religious practice. Nowadays the performances are very much contradictory between the Tibetan Buchen "crazy saint" and the audiences, especially the younger generation who received modern and scientific education. The religious practitioners often felt threatened by the enlightened, educated and urbane community (Sutherland \& Tsering, 2011, p. 22). From one point of view, Tibetan Buchen performance represents the embattled lineage of tradition that is struggling to survive in the modern world; on the other hand, it is 
hard to gain respect from people of other communities, as the performers are treated wrongly for distorting the facts rather than profound performance and entertainment. Oftentimes, they are mistaken for beggars on the streets rather than religious specialists.

Sutherland's photographs of Buchen performances are contemporary images potraying current living people. It is hard to categorise these images as portraiture and historical documents as they have been taken in recent years and photographed in an informal way (Sutherland \& Tsering, 2011, p. 20), where Buchen are requested to pose for him instead of captured in a live performance. According to Sutherland, Tibetans and Buchen think only colour images of them (Figure 4a), taken full-body and well-dressed, would be considered "well" photographed portraits, yet Sutherland's black and white portraits of Buchen (Figure 4b), taken in unguarded moments, would be considered by them (Tibetans and Buchen) as "poor" images.

I find the way we perceive and comprehend images closely related to our background, knowledge, belief, intention and experience. I am saying this because I find Sutherland's spontaneous images much more interesting and rewarding because they serve visual documentation appropriately and reveal truthful moments. However, I notice there are significant differences between my documentary images and Sutherland's documentary images (Figures 4a and 4b). All of my documentary images are captured in colour mode rather than black and white tone. I have no intention to show Tibetans' culture in a nostalgic mode as they are still living and surviving in the contemporary world. I think there is no need to exaggerate the feeling and moment of lost culture in the olden days (black and white) since the purpose is not historical documentation. Sutherland's works are presented to us as an archive of collaboration between Buchen themselves, inserting their own points of views of what could be an ideal visual record of their ritual performance, their theatre and their role. Therefore I see no point in repeating and photographing similar subjects that are profoundly researched by esteemed photographers like Sutherland, but inspired by his works and continue to push the boundary in order to discover creative visual representation that is uniquely distinguishable. As a result, I carry on looking at different documentary photographers' works related to the Western China to Himalayan region, in order to understand their approach and research motivation better.

Figure $4 a$. Disciples of a Crazy Saint

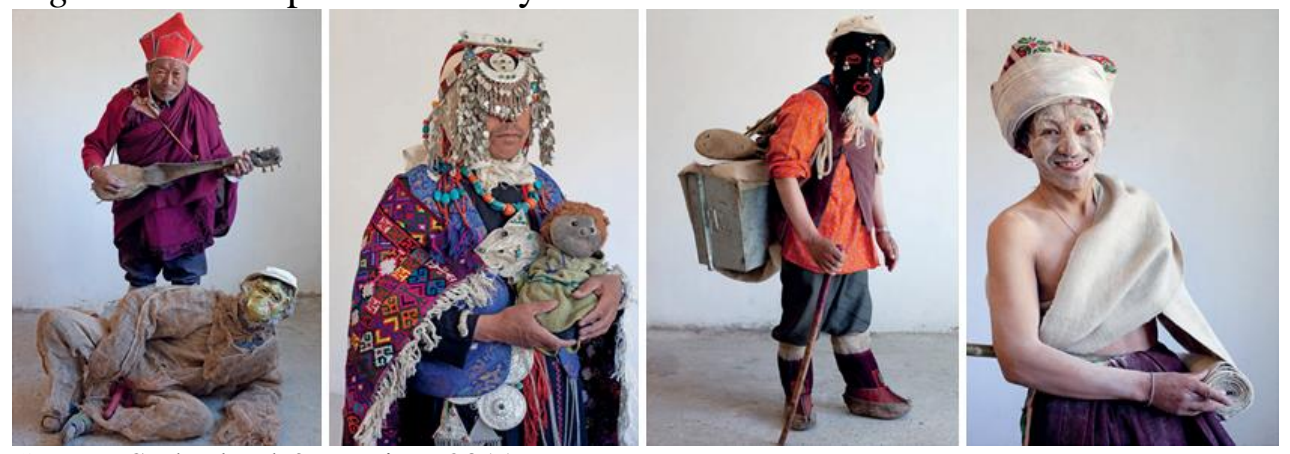

Source: Sutherland \& Tsering, 2011. 
Figure $4 b$. Disciples of a Crazy Saint
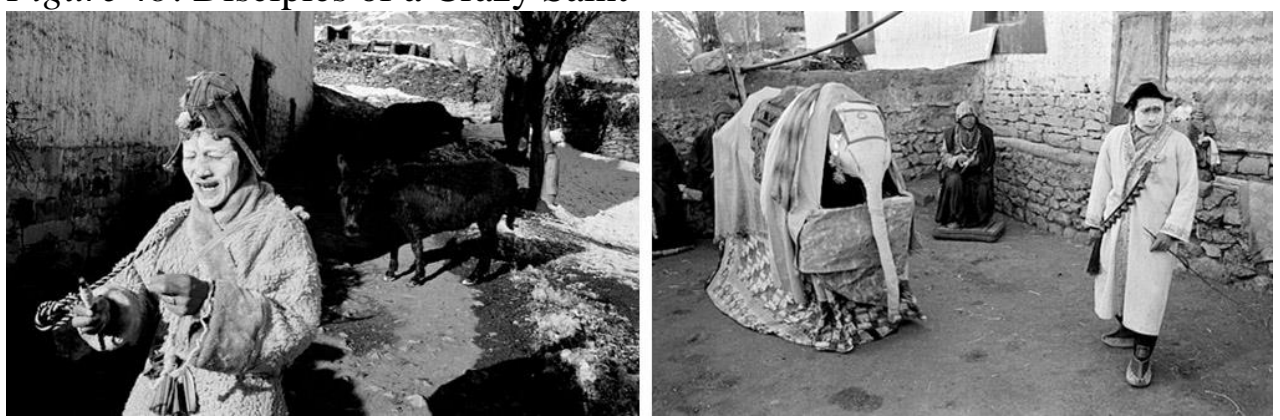

Source: Sutherland \& Tsering, 2011.

I find Arora's article "Framing the image of Sikkim" (Arora, 2009, p. 54-64) insightful because I witnessed Sikkim as being heavily promoted as a sanctuary for Tibetan Buddhism; yet, over the years, the demographics of the population and settlers seem to have changed if we look at the current residents of Sikkim. Border crossing is inevitable due to rivalry, economics and safety. Arora's article depicted Sikkim as highly framed as the Buddhist region in Northeast India, although Sikkim consists of twenty two Indo-Tibetan and Indo-Aryan ethnic groups. Sikkim's indigenous Buddhist visual images, such as postcards, tourist brochures and campaigns are disseminated locally and internationally, regardless of how those visual representations might have projected a biased image, without justification in terms of the contemporary ethnographic and socio-demographic group. In the past Sikkim was a Buddhist Kingdom and ruled by the Namgyal dynasty (1641-1975), however the current Nepali and Hindu residents and immigrants to Sikkim comprise around three-quarters, leaving only twenty percent or so of the population being Buddhist and considered indigenous.

Photographs do in a sense contain and constrain - frame, exclude and include according to photographer's perception and imagination. Photographs absolutely contain the power to convey and to deceive at the same time. Sometimes, the captured image and the conveyed message do not seem to go along well due to the internal and external distinction between the imagined, original content and context, and reproduction purposes. This happens when an image is being used as an advertisement, as a promotional picture such as postcards and posters the main purpose of which is to promote and seduce tourists - cultural tourism. I would not say cultural tourism is a bad idea, but updated visual representation is needed to portray current cultural transitions in order to distribute the reality, the correct image and facts of today's borderlands. Otherwise, we would be misled into looking at stereotyped and historically old images that are discordant with today's cultures and practices on the borderlands.

Ami Vitale is a photojournalist who has travelled to more than 85 countries, having spent plenty of time in Kashmir, India, where she anticipated and witnessed much dreadful violence, poverty, catastrophe, civil conflict and tension. Vitale believes in multiple viewpoints and that no single "truth" exists. When she is covering a story and assignment, she has always injected her own perspective to interpret the unveiled meaningful fact. In her Kashmir coverage (Figure 5), she 
intended to show the unseen side of the war. She witnessed the faces of war and people who often get caught in between.

My early phases of documentary and practical photographic works with documentary approaches (Figure 7) are rather similar to Ami Vitale's ideas of covering the borderlands. We do not seek the sensational and stereotyping war conflict visual. Both history and cultural background contributed a large context behind the content, where we spend a long period of time or frequently revisit, to understand the phenomenal and the ordinary in the same place.

Figure 5. Photography by Ami Vitale - Kashmir, India
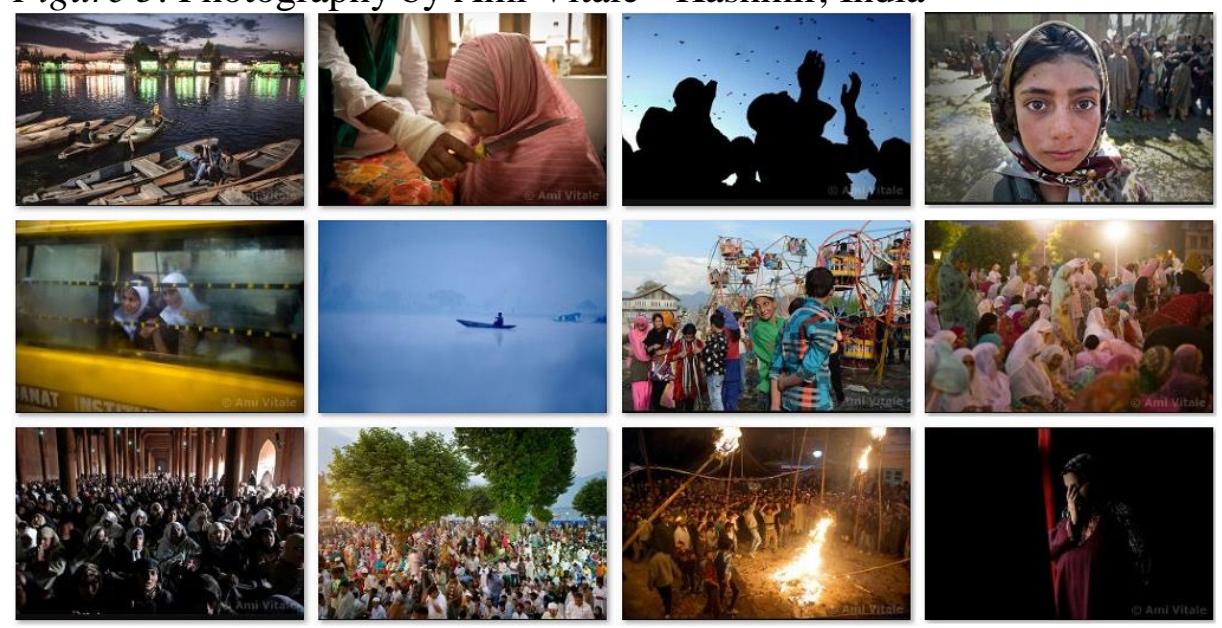

Source: Vitale, 2009.

Andy Grundberg explained that artists using other's images believe that there are still untapped images in the woods. The fact is that we go into the forest as hostages of a prejudiced image of the forest; what we grasp may have been done by other artists before (Grundberg, 1990, p. 172). Documentary photography has been utilised by photographers for over one hundred and fifty years for its ability to capture the exterior world and give witness to real physical events. The act of making photographs as evidence of acts, memorabilia, history and reflecting contemporary culture has been a powerful dimension of the world's culture since photography was invented. I find Ami Vitale's work remarkably classical, rooted and settled in the strictest sense of documentary command, where compelling and truthful visual is inevitable. I see many prominent documentary photographers are unable to break the documentary mold, where they continue to chase story after story without even attempting to switch direction and to see the subject afresh. Some photographers would rather resume their culmination drama over and over by bringing back similar images, but from different regions.

As I research further, I gain new perspective and interest by looking at different and unconventional documentary works. I find emerging documentary photographers like Carolyn Drake's works very promising and innovative. She too has extensively photographed the Xinjiang Autonomous Region, China. Although she utilised a photojournalism style in documenting the borderlands, in my opinion she has made more versatile progress by turning some of her photographs into fine art pieces (Figure 6). Drake would ask people to describe 
their own dreams in Islamic belief, and then ask people to leave messages in the journal and, finally, have people draw and sketch on her own printed photographic works. This would allow her to have less control over the imagery and mix it with someone else's narrative.

Figure 6. Documentary Photography by Carolyn Drake - Uyghur Autonomous Region, China
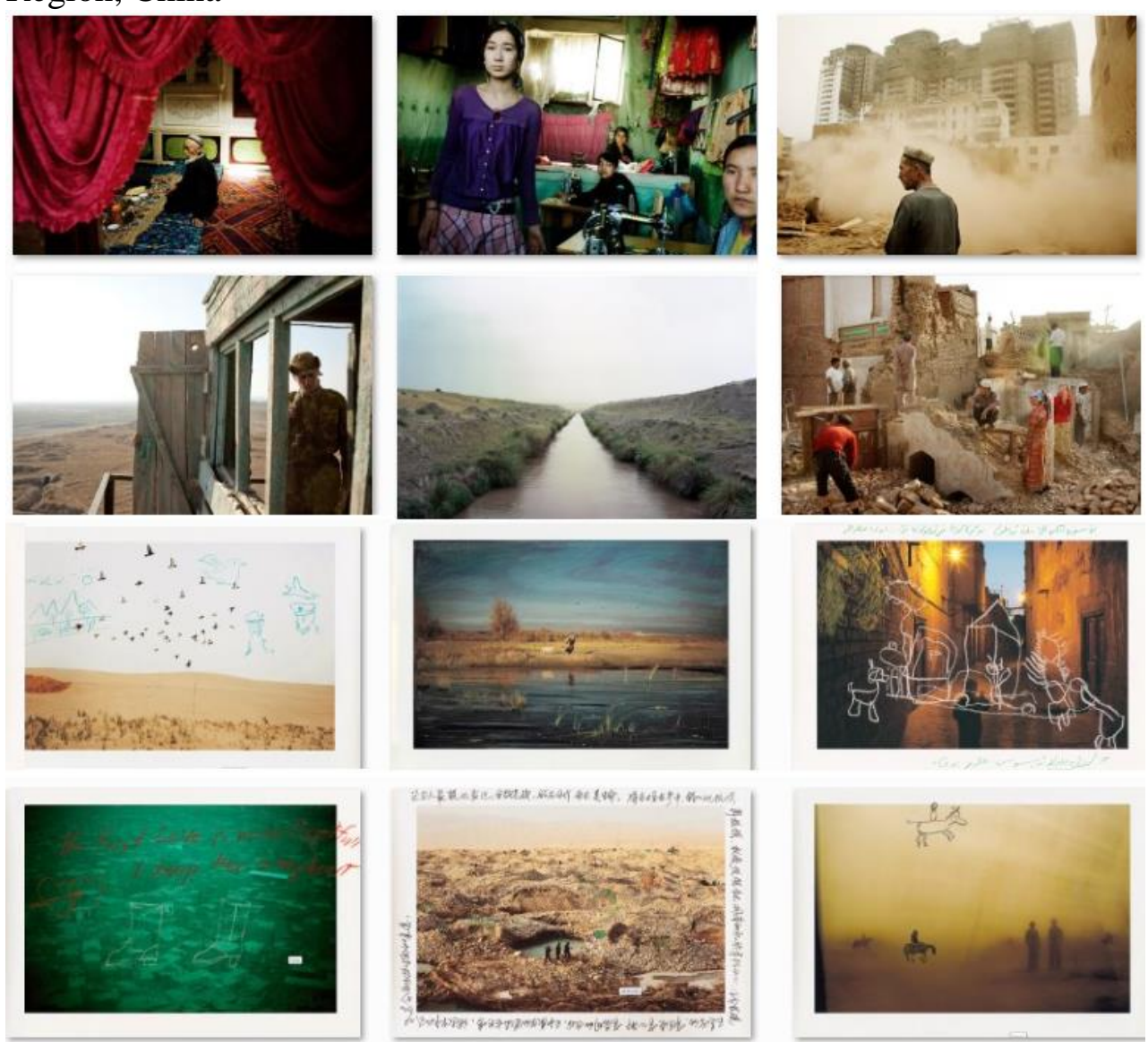

Source: Drake, n.d.

Drake's approach led me to experiment and relook at the borderlands subject anew. However, when photographic works leap into another genre, the definition is uncertain because the purpose, content and context are different. I found that Drake's works contained too much mixed information when she asked people to sketch on her own photographic prints. Would words and drawings provide us too much information and too many clues? Does photography need that many texts and scribbles of visuals to further describe it? In order to do so, I have departed from a documentary approach which primarily focuses on lifestyle and human conditions. I intend to seek a different and new borderlands representation in a subtle way. 
Figure 7. Documentary Photography (Portraits, lifestyle, cultural activities and festivals)
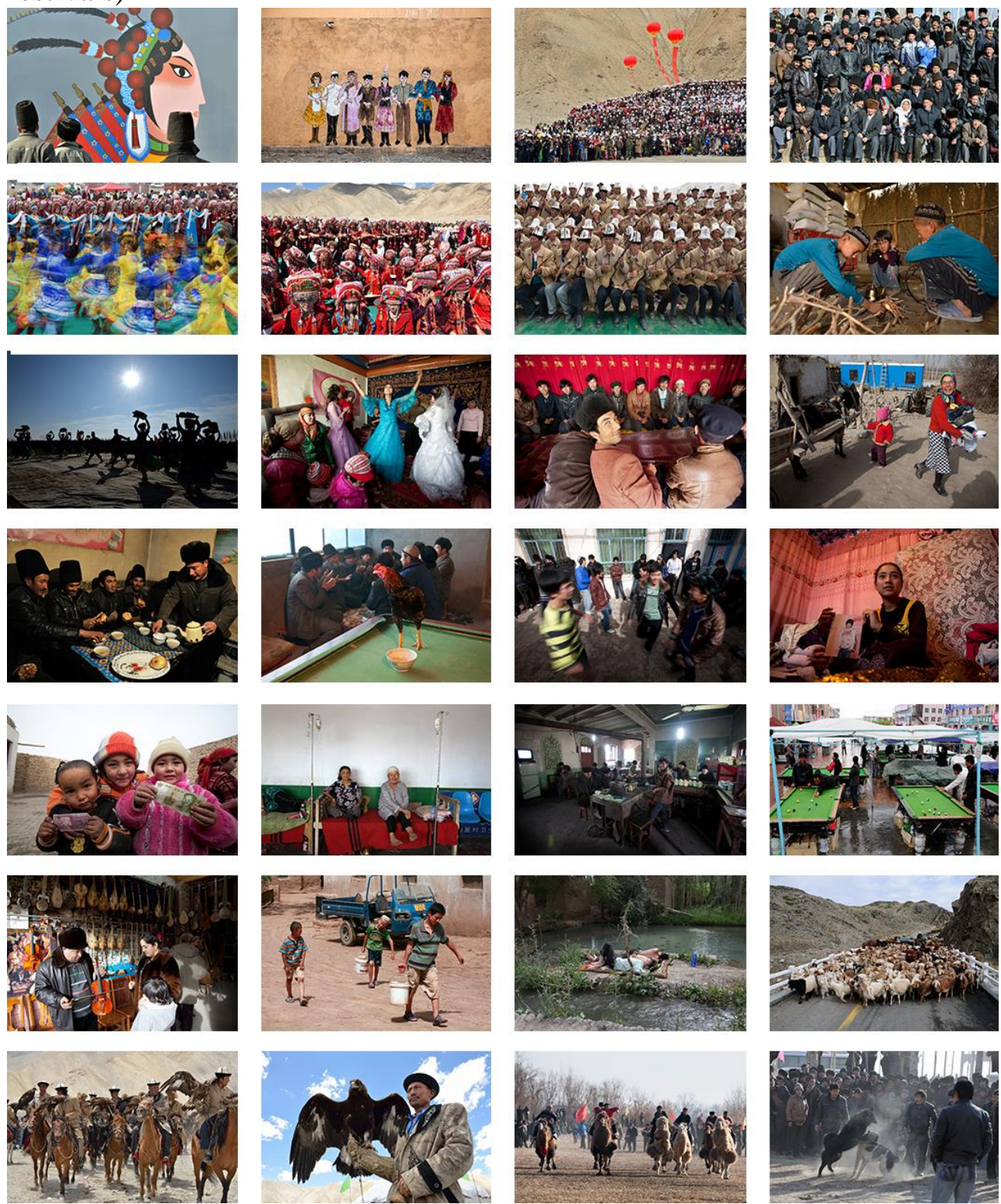

Source: Author's personal file.

\section{Stage 2: Realm of Endless Stretches}

Before embarking on the journey to photograph the Realm of Endless Stretches series, and after reviewing my documentary works over and over again, I find my documentary photography approach and colour photography straightforward: simply too real, too direct and too beautiful. On the other hand, I started to realise that I should further explore the borderlands passage in the restricted zones, rather than continue to photograph lifestyle, people, portraits and cultural activities (Figure 7). 
Therefore, I attempted to take a much higher ground view by plane and helicopter, photographing the Realm of Endless Stretches (Figure 10). It is because I realised that photography is oftentimes not only to attain reflective vista, instead to transcend facts of existence by composing original essence and composition of what remain before or ahead of us. It stretches the meaning of words, and extends thoughts and imagination. I find the blending landscape of borderlands fascinating. This is mainly because the aerial view of borderlands, from Western China to the Himalayan Region, is simply breathtaking and unique: the blending of massive landscape with seemingly endless stretches of grass land, dry land, crop fields and deltas looking like "earth veins", are connected to each other. It is difficult to tell the separating point of each country's borderland. The wide horizon at the borderlands can generate ambiguities of distance and position. Some of these areas are still considered undefined conflict zones. There is no clearly agreed map in these disputed areas. From far off, everything seems to blend very well together, resulting in a marvelous aesthetic of forms, colours and textures in fusion. Not only that, but also the forms of space (nature), time, and human action influence the various stages of borderland in the making. The stretches of endless landscape are going through a similar experience, either through the "Earth Changes" through a series of natural catastrophes or through human activity. Layers of memory (culture and history) are being stored and accumulated on this very ground (borderlands) that stretches beyond our prediction.

Many people see themselves as distinctive because of their capability of generating new ideas, amending and modifying old ones, and striving to fulfill their own goals. This sort of perception, motivation and aim puts humanity on the higher ground of reasoning, that a human is not merely an animal. On these borderlands, there are endless lessons and trials that teach us to generate new thoughts, analyse and realise them, and make decisive choices before acting upon them based on principles that are true to our beliefs, where we share and embrace each other (human and nature) positively. Most unfortunately, the results of unity are taken in the opposite direction by different central governments, unable to negotiate and see the benefits of a transnational perspective.

Photographing the borderlands landscape with an aerial view allowed the images to leap into another genre and convey the storytelling differently. To me, the Realm of Endless Stretches (Figure 10) would seem by far more like fine art and water colour painting than documentary photography. I thought it would serve as the philosophical representation of borderlands, because it encompassed all the elements and dilemmas that are very difficult to solve and explain at once, such as borderlanders' community interaction and communication, inseparable lands and resource-sharing, language, lifestyle and religion, borderlands security and governance, trade and businesses and many other similar and dissimilar issues. From a great distance, everything on the borderlands is amalgamated.

Having said that, I am well familiar with Andreas Gursky's large format architecture and landscape colour photographs. He often employs a high vantage point to capture his subject in a dense and well composed composition (Figures 8 and 9). During his study at Kunstakademie Dusseldolf, Germany, 
Gursky received effective training and influence from Hilla and Bernd Becher. He displayed a similar approach in his own large format documentation. There is a strong research pattern and systematic visual language in Gursky's photographic series. In his early photographic encounters he was inspired by John Davies, who photographed a lot of black and white street images and open spaces of urban landscape. Although I admired and appreciated the consistency of the powerful, condensed and detailed images of Gursky, I never had a second doubt that my images would be similar to his works until I displayed them individually on the gallery wall.

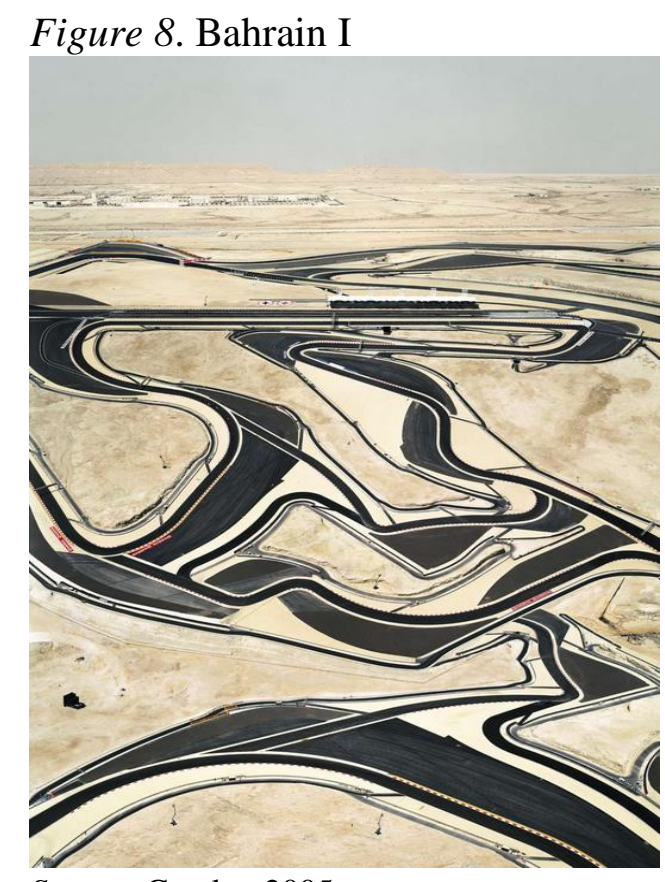

Source: Gursky, 2005.

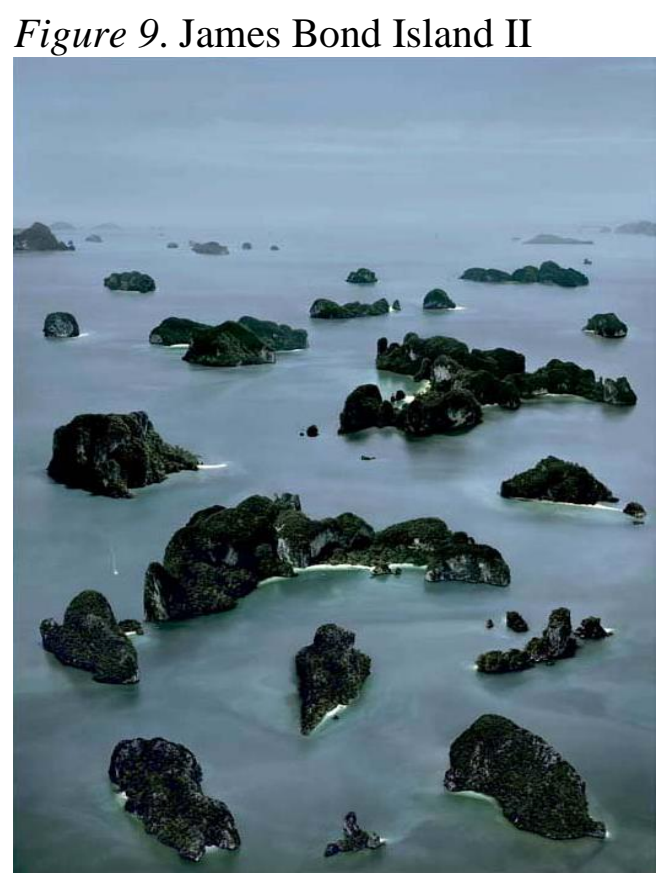

Source: Gursky, 2007.

I realised the Realm of Endless Stretches series could be the underdog in the long run, if I were to compare them with Gursky's aerial works, since his images have been displayed in major museums and galleries around the globe. Obviously I need to further experiment and capture distinctive images that are uniquely mine.

Furthermore, it would be complicated and time consuming if I were to explain each issue in detail from different sides of the borderlands. After several reasonable analyses and judgments, I decided that the Realm of Endless Stretches series was very broad and abstract in content, especially when I displayed them together (Figure 10). These images almost seem like they are taken from Google maps and satellite. In a sense, I thought the repetition of the blended borderlands landscape texture may serve better as an abstract art installation than as a photography series. This is because when the Realm of Endless Stretches is presented, these images do not reveal any appreciable information and recognisable locations without provided content and details. 
Figure 10. Realm of Endless Stretches

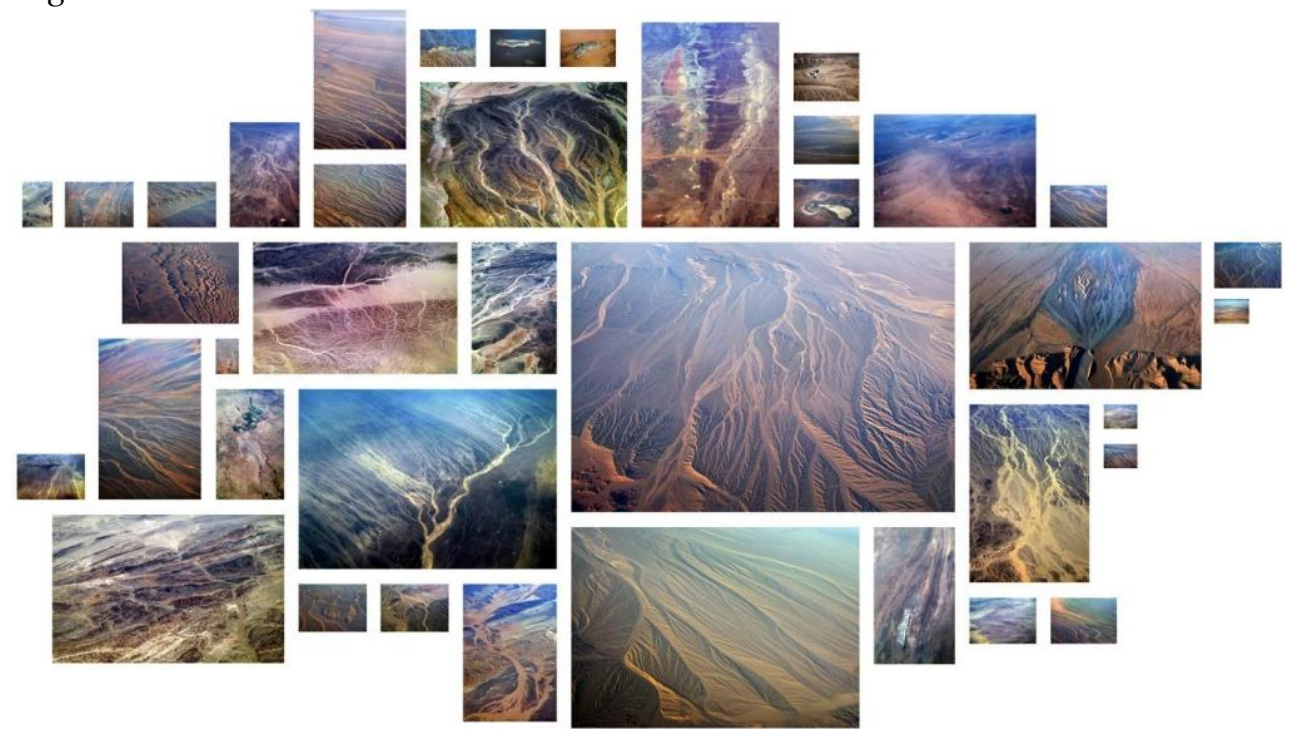

Source: Author's personal file.

\section{Stage 3: On the Road}

After confronting gravity, I am back to the ground of reality. I have decided to continue my discovery on the road of the borderlands passage. To me, life is like a road trip. Besides living with my own stories, it is interesting to listen and try to understand the stories of other individuals who have chosen to live their lives based on what they are passionate about. Hopefully, from these journeys, we can find stories that inspire and enlighten us. Therefore, I started my quest "On the Road", where I encountered the beauty and mystery of fog and mist later on.

Sometimes we are on the road trip of discovery because we are travelling somewhere in the hope of achieving a specific goal. As we experience our different journeys, they take us into a new body and we shed our old skin. We obtain a new soul and a new way of looking at life. I realise that it is the journey that makes me a man, not the goal. Perhaps the goal is important, not because of what it can give us when we attain it, but because of the life it forces us to live as we approach it.

I tried to photograph the roads that led me to the discovery of borderlands from Western China to the Himalayan Region. Of course, not all remote areas contain well-constructed roads and pathways. This is what makes freshly built tar roads connecting different borders in this region valuable to me. My approach to photographing the On the Road (Figure 13) series is to capture the "road" in various perspectives or display the composition within a large scale of borderland environment. It is like we - humans - have put a little scar on the landscape. Vibrant colour is important to me because it signals the vivid yet harsh living conditions on the borders. I try to photograph the road without humans: prioritizing the time and space relations from one end to another must be subjected to "Before" and "After"; we may gain insights and self-awareness 
when we are on a journey, unfolding our perception of life in a different perspective. Martin Lister (1995, p. 11) explained that instead of focusing attention upon a photograph as a final product, we need to consider its semiotics and social hybridity. Its meanings and power are not a singular, essential and inherent quality. I can see and come to understand what he means when I am "On the Road".

These roads serve the purpose by connecting borderland residents and activities. It is an unbelievably long journey! I must say that I admired and appreciated the road construction workers who strenuously built the roads at the borderlands in every weather condition I came to witness. Without these roads, journey in this vast borderland region would be harsh and unthinkable!

Figure 11. Sebastiao Salgado, Region of Lake Faguibine

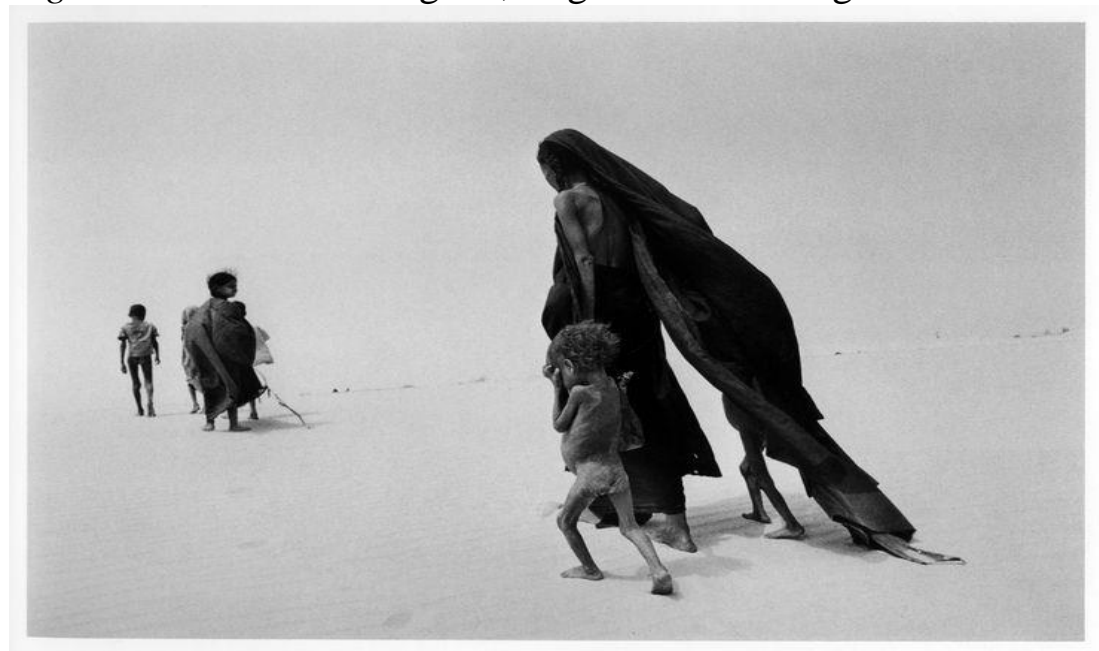

Source: Salgado, 1985.

I think photographers should carry out some responsibility and awareness toward their captured images. Sahel, The End of The Road, by documentary photographer Sebastiao Salgado, evoked a very dramatic, painful and sad human experience (Figure 11 and Figure 12). It is a total silent drama of photography which I felt and confronted as hopeless tragedy when our earth has so much to offer, yet humanity is lost and neglected in different continents of the world. Salgado's compelling and dramatic black and white images bring us to witness the world's unimagined and astounding reality. On the contrary, my On the Road series (Figure 13) depicted a silent, calm, colourful, inviting yet puzzling direction toward the frontier, when the road leads to uncertainty at the conflicted zones. I come to realise that I need to capture the subtle and mysterious ambience of the disputed borderlands that contain realistic qualities to display the resonance and meanings that are timeless, rather than moments that provide a historical and direct cultural message. 
Figure 12. Sebastiao Salgado, Lake Faguibine Dried up with the Drought and Invasion of the Desert, Mali

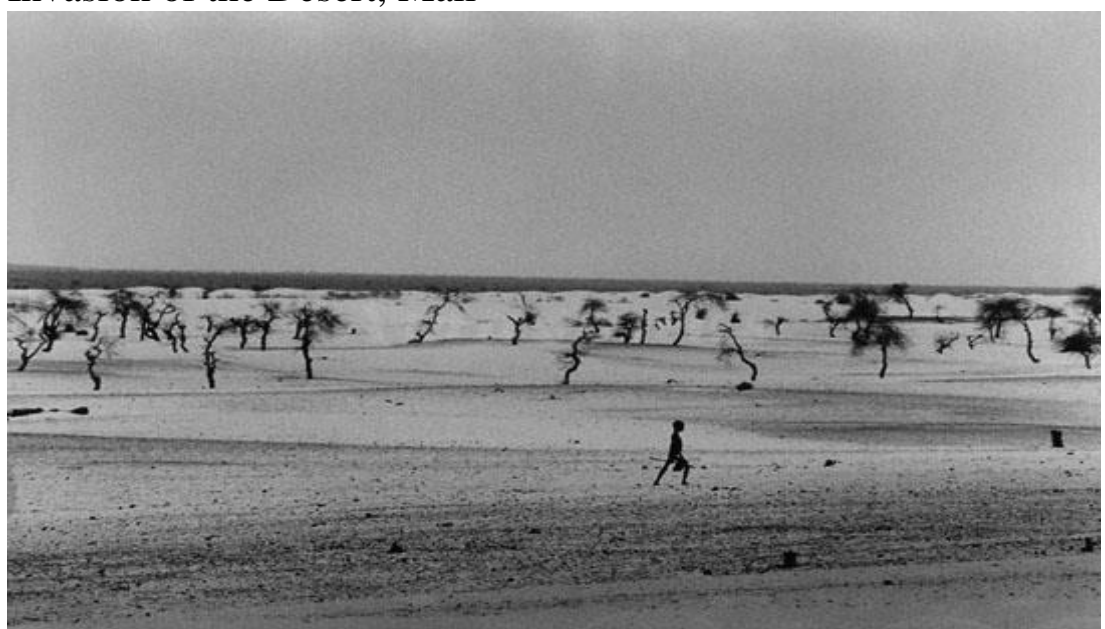

Source: Salgado, 1985.

Figure 13. On the Road
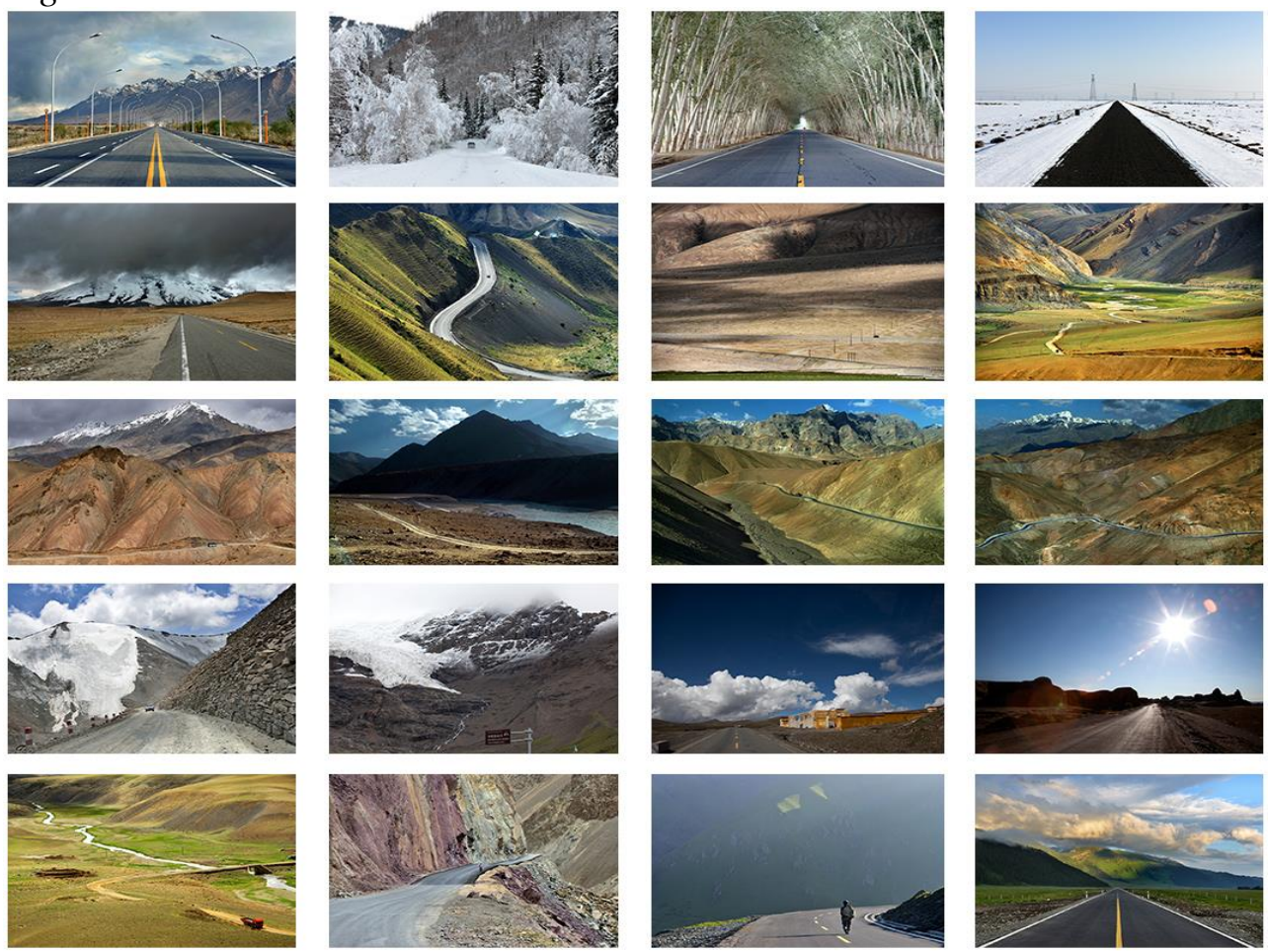

Source: Author's personal file.

\section{Stage 4: In and Out of the Mist}

By researching differently, more deeply, and revisiting the same subjects, the On the Road photography series led me to In and Out of the Mist. Like a butterfly out of a cocoon, the In and Out of the Mist photography series could be contemporary art that has references to twenty first century culture and visual landscape. By pushing further away from the reality of space and time, I 
discovered fog and mist mysteriously provided me the perfect surreal visual appearance that I had long been waiting for. Photography is more than cameras and lens; it is a magical time machine. The timing could not have been better, especially when I encountered the fog and mist conditions on the borderlands passage while I was photographing the roads that connect different borders in this region. I realised that fog and mist are the perfect synthesis of colour and black and white photography, where fog and mist transform colour photography into a neutral grey tone, but still in colour. I try to capture my photographic works differently by attempting to inject a distinctive suspension to the viewer for a mysterious yet truthful borderlands journey, through landscapes that are shrouded in mist and fog.

After my long search and research, I found many individual and singular fog and mist photographs and artworks regarding landscape, architecture and urban subjects. Nonetheless, there are yet photographers who see and use fog and mist as their metaphor and fundamental concept to photograph the borderlands. I am finally convinced that the In and Out of the Mist series could be avant-garde and exceptional. These fog and mist images captured in the conflicted borderlands could be fresh and contemporary because they encompass an imminent dilemma happening in the current borderlands from Western China to the Himalayan Region, yet the anxious condition is soothing, peaceful and problem-free through the ephemeral fog and mist appearance.

Due to my background in animation and video, the cinematic influence can be observed in most of the In and Out of the Mist photographs, where they do seem like stills from an epic journey. Some of these works look like they are from an extended narrative, as if they are single arrested moments from a larger visual experience. Each work (Figure 14) draws the viewer in to consider broader issues beyond the immediate connection of visual facts. When we are confronted by a lack of details, such as our experiences of a feeble dawn light or a total white-out in fog, we can have a reaction of anxiety. While looking at the works, one may imagine oneself in the foggy scene, not knowing where and what to expect next. Not only that, but some of the works from the unfamiliar borderlands may present an apocalyptic atmosphere. I strive to show the ordinary and unfamiliar in the most compelling dimension of surrealism. At the same time, all the works appeared in soft tones of grey, but actually they present soft tonal gradations of blue, green, brown and purple. By closely searching through the works in detail, the viewer would be rewarded with details of intense colour.

In and Out of the Mist also reveals other issues, such as global warming, isolation of peoples, humanity's relationship with architecture, and cultural connections. Of course, the most significant would be the reflection of humankind's influence on the natural landscape at the borderlands, and the drama that unfolds when fog and mist invade the borderlands.

The definite location is no longer important in the strictest sense of documenting the vast borderlands from Western China to The Himalayan Region. When one encounters fog and mist that are out of one's regular routine and rhythm, In and Out of the Mist can result in sudden poetic and romantic 
visual appearances that allude to the vast variety of landscapes around the borderlands (Figure 14). My main intention was not to specify or reveal the borderland location in the strictest sense, because I see that humanity, humanmade and natural relationships are inseparable. The separation and discrimination of "who is who" and "who is what" may not be that important at the borderland, since borderlanders who live there all depend on the Himalayan Plateau's natural resources. After all, the temporary fog and mist effects are soothing in some highly-armed and ongoing disputed zones.

Figure 14. In and Out of the Mist (Borderlands)
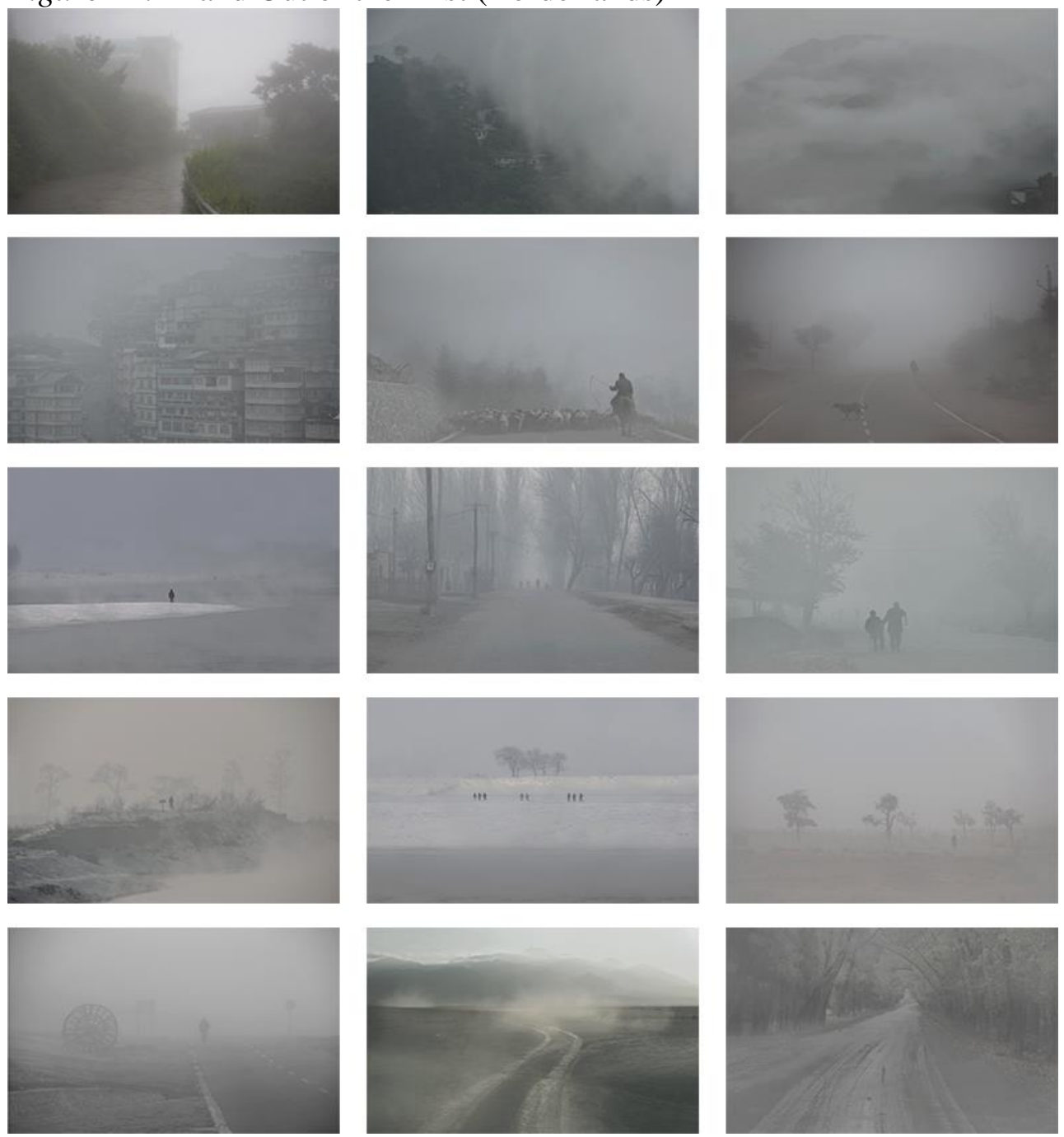

Source: Author's personal file. 


\section{Conclusion}

The use of photography as a medium to document the borderland is not new. However, after an extensive period of research in this region, the discovery of the fog and mist intervention in photography could push documentary photography away from its original and classical context. It is no longer straightforward recording, because there is a need for creative recognition of man-made and natural elements in fusion, to generate a surrealistic scene in a realistic atmosphere. Practical research towards In and Out of the Mist: An Artistic Investigation of Borderland and Community (From Western China to the Himalayan Region) prove that photography is more than a medium of documentation. With the right moment while photographing the borderlands, under fog and mist intervention, a realistic and familiar atmosphere may suddenly turn into a surrealistic, magical and strangely familiar stage. Most of the time, the appearance and disappearance of fog and mist happens rapidly. Under such circumstances, photography is still the best medium to instantly capture these mysterious moments.

Documentary photographers' concepts and approaches which have been applied to photographing the borderland are predominantly based on the historical background and cultural context in their photographs' content. Everything that is photographed is clearly depicted in the documented photographs' content. The clear and obvious information is inevitable. All of the documentary photographers who photographed the borderland reject unclear and puzzling visuality. They seem prejudiced against the sending of an unclear message to the viewer. On the other hand, In and Out of the Mist broke the mould of borderland documentary photography by capturing the poignant, saturated moments and puzzling relationships of human, man-made structures and nature in the borderland. Photographing in fog and mist conditions is not an easy task. In order to express the ambiguous aesthetic of borderlands that I desired, different representations such as Realm of Endless Stretches and On the Road series have been used to envision the borderless borderland possibility. In and Out of the Mist, demonstrated a different artistic quality compared to any documentary photography on borderlands. This unique approach serves as the best natural, local and external medium that neutralises the borderlands' complexity and tension in any conflict areas. Under such In and Out of the Mist circumstances, the third space forms silently - a universal border culture. Fog and mist represent my visual and theoretical metaphor, as well as serving as a medium to meditate on the on-going conflicts on borderlands in a silent and mysterious mode.

The fact that there is a shared understanding of what it means to live in the borderlands indicates to us that differences remain the main concern in the twenty-first century. This research, In and Out of the Mist: An Artistic Investigation of Borderland and Community, will serve as a metaphoric and artistic study to reject violence, racial discrimination and status differences targeted against borderlanders. The borderlands of this region are a wide open space. The borderlands should be embraced and turned into safe, accessible and familiar transnational space. 


\section{References}

Arora, V. (2009). Framing the image of Sikkim. Visual Studies, 24(1), 54-64.

China. (1996). Special Economic Zones. Retrieved from https://ces.to/5hUMz3. [Accessed 30 Jan 2010].

Drake, C. (n.d.). Becoming Chinese. Retrieved from https://ces.to/2ECqUH. [Accessed 31 Dec 2012].

Goodreads. (n.d.). Henri Cartier-Bresson Quotes. Retrieved from https://ces.to/XpYIkV. [Accessed 17 June 2011].

Grundberg, A. (1990). Crisis of the Real. New York: Aperture.

Gursky, A. (2005). Bahrain, I. Retrieved from https://ces.to/bTFvm9. [Accessed 10 August 2015].

Gursky, A. (2007). James bond Island II. Retrieved from https://ces.to/GynHda. [Accessed 10 August 2015].

Jameson, F. (n.d.). Postmodernism and Consumer Society. Retrieved from https://ces.to/ Jk6S1Z. [Accessed 20 March 2015].

Linfield, S. (2012). Cruel Radiance. University of Chicago Press. Retrieved from https://ces.to/Ser7df. [Accessed 28 September 2013].

Lister, M. (1995). The Photographic Image in Digital Culture. London: Routledge.

Pachmanova, M. (2006). Mobile Fidelities: Conversations on Feminism, History and Visuality. KT Press. Retrieved from https://ces.to/gVQBYi. [Accessed 23 June 2015].

Rosler, M. (2008). The Gray Drape. Retrieved from https://ces.to/6KD1jX. [Accessed 24 June 2015].

Salgado, S. (1985). SAHEL - Region of Lake Faguibine, Mali. Retrieved from https://ces. to/xOzsv5. [Accessed 11 August 2015].

Sutherland, P. \& Tsering, T. (2011). Disciples of a Crazy Saint: The Buchen of Spiti. Pitt Rivers Museum, University of Oxford, Oxford, UK.

Verve, P. (n.d.). The New Breed of Documentary Photographers. Retrieved from http://vervephoto.wordpress.com/ [Accessed 15 June 2011].

Vitale, A. (2009). Kashmir. Retrieved from https://ces.to/iIdtob. [Accessed 24 Dec 2012]. 